ISSN 0258-7122 (Print), 2408-8293 (Online)

Bangladesh J. Agril. Res. 43(2): 253-266, June 2018

\title{
GENETIC DIVERSITY IN AUS RICE (Oryza sativa L.) GENOTYPES OF BANGLADESH
}

\author{
N. AKTER ${ }^{1}$, H. BEGUM, M. Z. ISLAM, M. A. SidDiQUE \\ AND M. KHALEQUZZAMAN
}

\begin{abstract}
Genetic diversity in 31 traditional Bangladeshi Aus rice genotypes were studied under transplanted condition through Mahalanobis $\mathrm{D}^{2}$ statistic for grain yield and yield contributing characters. The genotypes were grouped into five clusters. The inter-cluster distances were higher than intra-cluster distances indicating wider genetic diversity among the genotypes of different clusters. The intracluster distances were lower in all the cases reflecting homogeneity of the genotypes within the clusters. The cluster II contained the highest number of genotypes (08) and the cluster I and III contained the lowest (05). The highest intra-cluster distance was noticed for the cluster II and the lowest for cluster IV. The highest inter-cluster distance was observed between cluster II and V followed by cluster III and V, cluster I and V and the lowest between cluster I and III. Regarding inter-cluster distance, the genotypes of cluster V showed high genetic distance from all other clusters. The genotypes from cluster $\mathrm{V}$ could be hybridized with the genotypes of other characters of other clusters for producing transgressive segregants. The highest cluster means for yield, effective tiller number and grain length, were obtained from cluster I; whereas the lowest mean value for yield, culm length, plant height and grain breadth were found in cluster II. Therefore, genotypes under cluster I, cluster II and cluster V might be selected for future breeding program as parents for crossing to produce new recombinants with desired traits.
\end{abstract}

Keywords: Genetic diversity, $\mathrm{D}^{2}$ analysis, cluster analysis, rice (Oryza sativa $\mathrm{L}$ ).

\section{Introduction}

Rice (Oryza sativa L.) is a self-pollinated cereal crop of Poaceae family under the order Cyperales. It is considered as a major crop in Bangladesh as it constitutes $90.56 \%$ of the total food grain (rice, wheat \& maize) production (Anon., 2015). Although Bangladesh is now on the verge of attaining self sufficiency in cereal production, there is still a large gap between the production and demand. Achieving self-sufficiency in rice production and maintaining price stability are important in countries where rice provides food security and generates employment and income for people (Hossain, 1995). Rice area coverage includes $13 \%$ upland ecosystem, $11 \%$ deepwater ecosystem and 25\% rainfed lowland ecosystem of the total rice area (Fukai and Cooper, 1995). Upland rice (Aus) is in

${ }^{1}$ Genetic Resources and Seed Division, Bangladesh Rice Research Institute (BRRI), Gazipur-1701, Bangladesh. 
extreme emphasis for its short duration because, crop with less growth duration is good for accommodating more than three to four crops a year.

Bangladesh has a good source of indigenous rice cultivars with two million hectares coverage, while the HYV and hybrids occupy eight million hectares and one million hectares, respectively (Talukder, 2011). Knowledge of genetic diversity among existing cultivars of any crop is essential for long term success of breeding programme and maximizes the exploitation of the genetic resources (Belaj et al., 2002). Hybridization is one of the major tools for the improvement of a crop that needs the analysis of genetic diversity for the selection of parents (Singh, 1983). Moreover, evaluation of genetic diversity is important for the source genes of particular traits within the available germplasm (Roy and Panwar,1993).

With the development of advanced biometrical techniques such as multivariate analysis based on the Mahalanobis (1936) statistics, quantification of divergence among the biological population and assessing the relative contribution of different components to the total divergence at intra and inter-cluster levels have now become possible. Such study also selects the genetically diverse parents to obtain the desirable recombinant in the segregating generations. Hybridization is a common practice for combining the desirable characters of two or more lines or varieties into a single variety. In several cases, the progenies become far superior to the parents in vigor i.e. hybrid vigor or heterosis. In addition, crossing in moderately diverse parents also showed the maximum heterosis (Chauhan and Singh, 1982). The necessity of principal component analysis (PCA), principal coordinate analysis (PCoA), non-hierarchical clustering and canonical vector analysis (CVA) for measuring the degree of divergence has been established by several investigators in rice and other crops (Selvakumar et al., 1989; De et al., 1988; Pathan et al., 1993).

More than 8000 rice germplasm have been registered in BRRI genebank (BRRI, 2015). But information on grain yield and yield contributing characters in traditional rice is scanty. Keeping this in view, the present study was focused to assess the extent of genetic diversity in 31 traditional aus rice varieties. This will help classify those into clusters to select varieties as prospective parents to develop transgressive segregants.

\section{Materials and Methods}

A total of thirty one rice genotypes collected from the genebank of Bangladesh Rice Research Institute (BRRI), Gazipur were grown in transplanted condition (Aus) in 2015 (Table 1). The trial was conducted in a randomized complete block design with three replications. Twenty days-old seedlings from each entry were transplanted using single seedling per hill in $2.4 \mathrm{~m}^{2}$ plot following $25 \mathrm{~cm}$ and 20 $\mathrm{cm}$ space between rows and plants, respectively. Fertilizers were applied @ 60:20:40: $12 \mathrm{~kg} \mathrm{~N}, \mathrm{P}, \mathrm{K}$ and S per hectare (BRRI, 2015). All the fertilizers except 
$\mathrm{N}$ were applied at final land preparation. Nitrogen was applied in three equal splits, at 15 days after transplanting (DAT), at 35 DAT and just before flowering. Intercultural operations and pest control measures were done as and when necessary. At maturity, grain yield ( $\mathrm{g} / \mathrm{hill}$ ) was taken and adjusted at $14 \%$ moisture level. Ten plants from each entry were randomly selected for recording data on Flag leaf length $(\mathrm{cm})$, Flag leaf width $(\mathrm{cm})$, Plant height $(\mathrm{cm})$, Days to flowering, Days to maturity, Panicle length $(\mathrm{cm})$, Effective tiller (no.), Filled grains per panicle (no.), Unfilled grains per panicle (no.), Grain length (mm), Grain breadth $(\mathrm{mm})$, Length-breath ratio, 1000 grain weight $(\mathrm{g})$ and Yield/hill (g). The data were analyzed following principal component analysis (PCA) and Mahalanobis's (1936) generalized distance $\left(\mathrm{D}^{2}\right)$ extended by Rao (1952). Intra and inter cluster distances were calculated by the methods of Singh and Chaudhury (1985). All statistical analyses were carried out using Genstat 5.5.

Table 1: Information on place of collection and local name of the aus rice landraces

\begin{tabular}{l|l|l|l|l|l}
\hline $\begin{array}{r}\text { Sl. } \\
\text { No. }\end{array}$ & \multicolumn{1}{c|}{ Genotypes } & $\begin{array}{c}\text { District of } \\
\text { Collection }\end{array}$ & Sl. No. & Genotypes & $\begin{array}{c}\text { District of } \\
\text { Collection }\end{array}$ \\
\hline 1 & Begun bichi & Kushtia & 17 & Raitul & Barguna \\
2 & Hashikalmi & Kushtia & 18 & Kuchmuch & Barguna \\
3 & Kalo dhan & Kushtia & 19 & Puitra Aijang & Barguna \\
4 & Aus dhan & Kushtia & 20 & Boula & Barguna \\
5 & Digha Bawalia & Kushtia & 21 & Chaina & Barguna \\
6 & Hanuman jata & Kushtia & 22 & Saith shail & Barguna \\
7 & Itcrie & Meherpur & 23 & Sadey Aus & Barguna \\
8 & V-2 & Meherpur & 24 & Mallika & Barguna \\
9 & V-3 & Meherpur & 25 & Adub alli & Barguna \\
10 & V-4 & Meherpur & 26 & Bar dhan Aus & Barguna \\
11 & Parangi & Rajbari & 27 & Kalo Aus & Barguna \\
12 & Sanda mioni & Rajbari & 28 & Bardhan Aus M-741 & Barguna \\
13 & Jaymori & Rajbari & 29 & H-171 & Barguna \\
14 & Kalo hizli & Rajbari & 30 & H-12 & Barguna \\
15 & Minikit & Barguna & 31 & Kadidet & Barguna \\
16 & Parangi & Barguna & & & \\
\hline
\end{tabular}

All the genotypeses are new collection (NC) having same origin i.e. Bangladesh.

\section{Results and Discussion}

\section{Qualitative traits characterization}

One of the aims of the present study was to identify distinct qualitative traits variation among the tested aus rice landraces. Variation was found in 19 of the 22 qualitative traits under studied except ligule shape, collar colour and auricle colour (Table 2). 


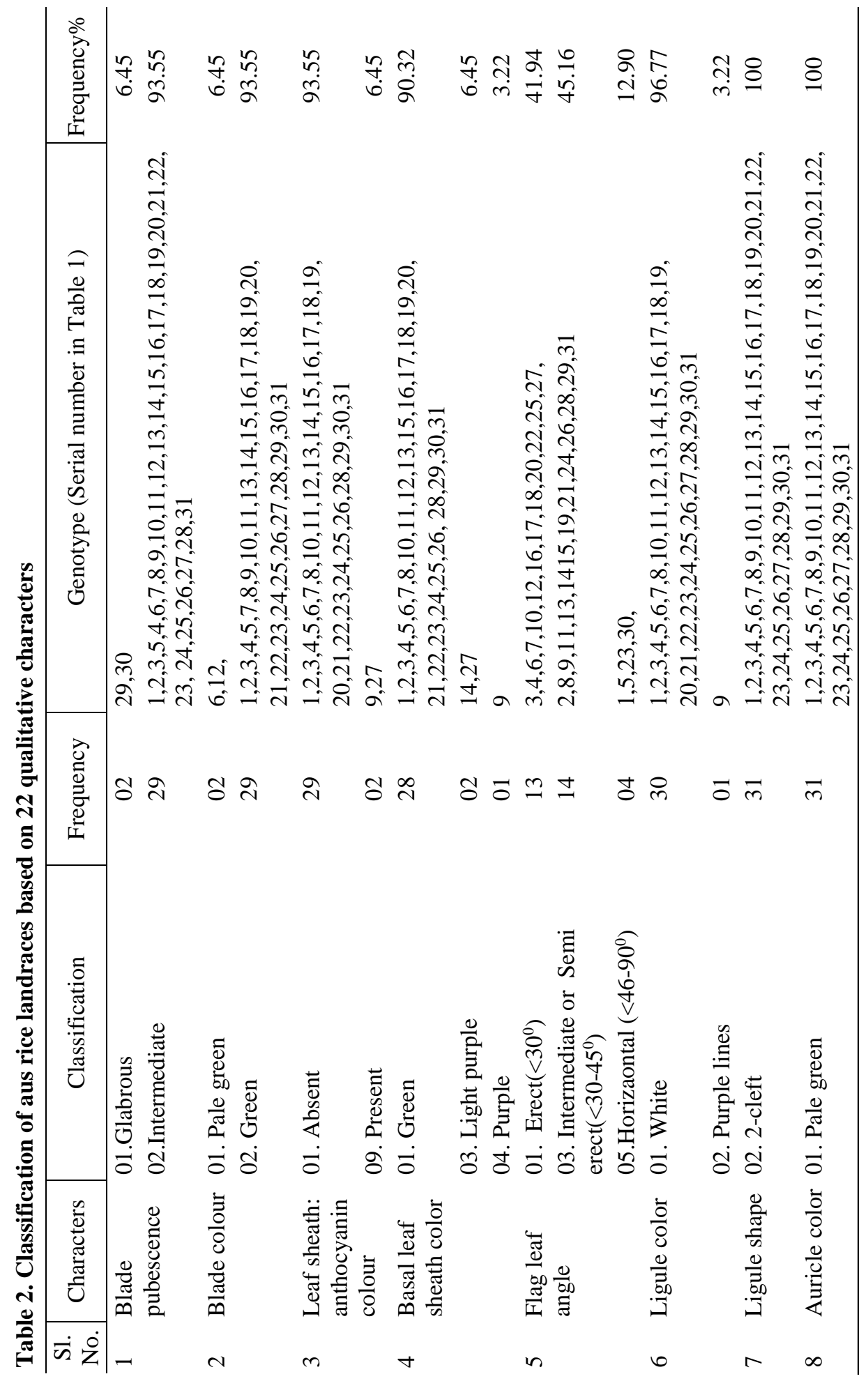




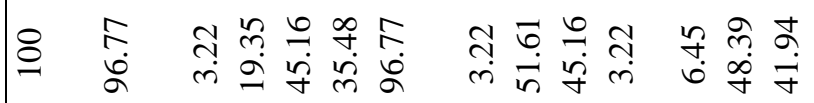

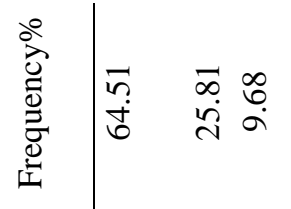

กิ

กิ

$\stackrel{2}{2}$

$\stackrel{\infty}{=}$

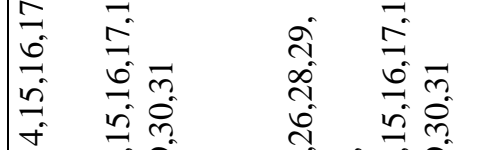

ल चे मेंतेंते

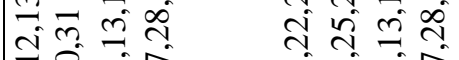

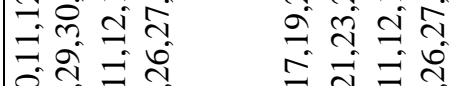

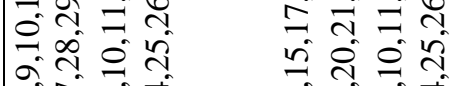

कंते के के के

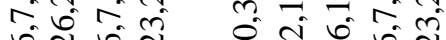

$\begin{array}{lll}n & 0 \\ n & n & 0\end{array}$

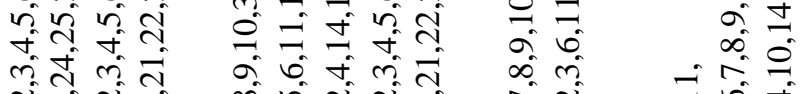

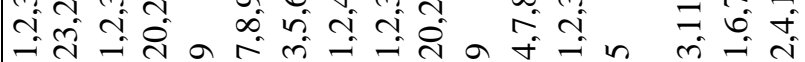

க

ทे ते ते

ते तु तू ते

ते

กิ

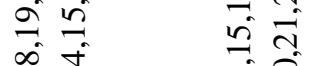

ले ले ते

= त I

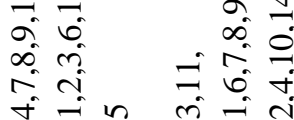

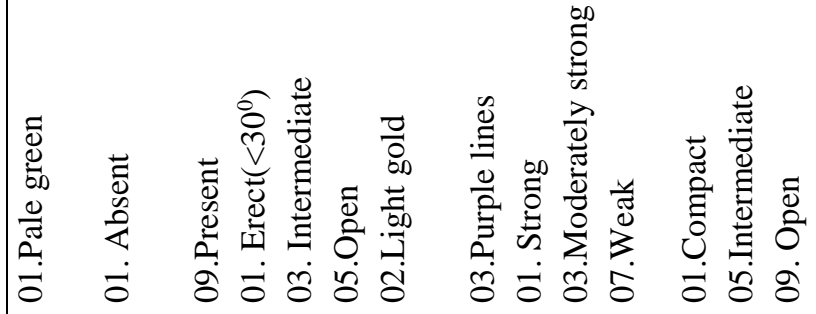

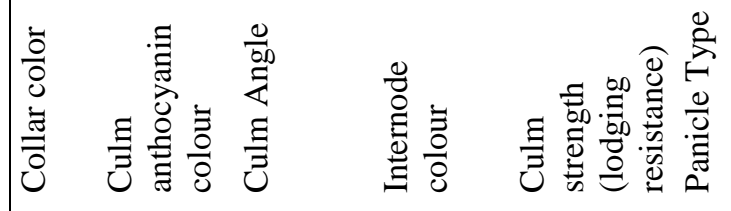

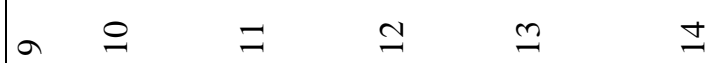

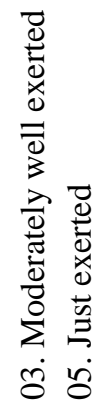

离

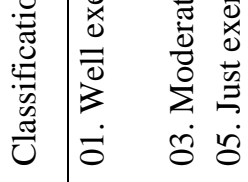

这

证

$\dot{\bar{s} \dot{z}} \bumpeq$ 





Most of the characterized landraces $(93.55 \%)$ exhibited intermediate leaf blade while the rest of the landraces exhibited glabrous $(6.45 \%)$ leaf blade pubescence. About $93.55 \%$ of the evaluated aus rice landraces exhibited a blade colour green while the remaining landraces $(6.45 \%)$ were pale green. Data in Table 2 also demonstrated variation in flag leaf angle where the percentage of aus rice landraces with erect, semi erect and horizontal flag leaf were $41.94 \%, 45.16 \%$ and $12.90 \%$, respectively. The qualitative characters showing higher variability were culm angle $(19.35 \%$ erect, $45.16 \%$ intermediate and $35.48 \%$ open), internode color (96.77\% light gold and 3.22\% purple lines), culm strength (51.61 $\%$ strong, $45.16 \%$ moderately strong and $3.22 \%$ weak), panicle type $(6.45 \%$ compact, $48.39 \%$ intermediate and $41.94 \%$ open $)$, panicle exsertion $(64.51 \%$ well exserted, $25.81 \%$ moderately well exserted and $9.68 \%$ just exserted), awns in the spikelet (58.06\% absent and $41.94 \%$ present), distribution of awning (25.81\% tip only, $6.45 \%$ upper half and $9.68 \%$ whole length), awn color (38.71\% straw and $35.48 \%$ black).

Most of the tested landraces possessed straw lemma and palea colour (48.39\%), red seed coat colour $(45.16 \%)$, intermediate type leaf senescence $(90.32 \%)$. The present study exhibited high variability in most of the observed qualitative traits of aus rice landraces. Similar types of work was also reported by other authors (Bisne and Sarawgi, 2008; Moukoumbi et al., 2011; Ahmed et al., 2016; Mau et al., 2017; Akter et al., 2017).

\section{Quantitative traits characterization}

Eigen values (latent roots) and percentage of total variation accounted for them obtained from principle component analysis are presented in Table 3. The result exposed that the first five components in the PCA with eigen values $>1$, contributed $80.37 \%$ of the total variations among the genotypes for 14 morphological characters.

Islam et al. (2016) observed that the first nine axes accounted about $90 \%$ of the total variations by PCA in 113 aromatic and fine grain rice landraces. On the other hand, Sohrabi et al. (2012) and Chakravorty et al. (2013) observed the contribution of 76.7 and $75.9 \%$ of the first six and four components, respectively to the total variation in rice. On the basis of principal component axes I (PCA score 1) and II (PCA score II), a two dimension chart $\left(Z_{1}-Z_{2}\right)$ of the 31 genotypes was constructed where the genotypes are presented in Fig.1. As per the scattered diagram the genotypes were apparently distributed into five clusters. Similar findings also reported by Habib et al. (2005) for traditional Biroin rice germplasm. 
Table 3. Latent roots (Eigen Values) and their variation in 14 quantitative characters in 31 aus landraces

\begin{tabular}{c|c|c|c}
\hline $\begin{array}{c}\text { Principal component } \\
\text { axes }\end{array}$ & Latent roots & $\begin{array}{c}\text { Variation } \\
(\%)\end{array}$ & Cumulative \% of variation \\
\hline PC 1 & 4.28 & 30.57 & 30.57 \\
PC 2 & 2.64 & 18.88 & 49.45 \\
PC 3 & 1.79 & 12.79 & 62.24 \\
PC 4 & 1.43 & 10.24 & 72.48 \\
PC 5 & 1.10 & 7.89 & 80.37 \\
PC 6 & 0.76 & 5.41 & 85.78 \\
PC 7 & 0.61 & 4.36 & 90.14 \\
PC 8 & 0.58 & 4.13 & 94.27 \\
PC 9 & 0.34 & 2.44 & 96.71 \\
PC 10 & 0.30 & 2.14 & 98.85 \\
PC 11 & 0.13 & 0.93 & 99.78 \\
PC 12 & 0.03 & 0.18 & 99.96 \\
PC 13 & 0.01 & 0.04 & 100 \\
PC 14 & 0.00 & 0.00 & 100 \\
\hline
\end{tabular}

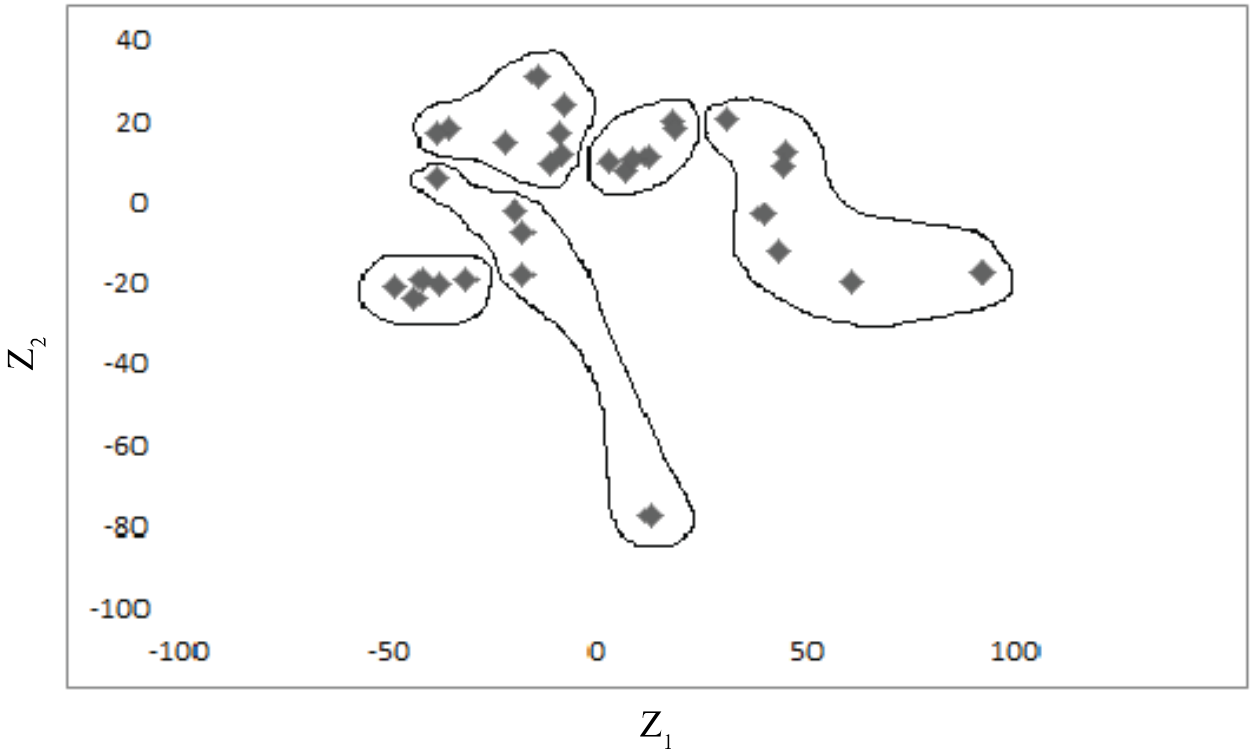

Fig. 1. Scatter diagram of 31 aus rice genotypes based on their principal component scores superimposed with clusters. 
Based on the degree of divergence, 31 genotypes were grouped into five clusters on the basis of cluster analysis (Table 4). Islam et al. (2016) reported ten clusters, Ahmed et al. (2010) and Islam et al. (2014) reported six clusters each and Siddique et al. (2013) reported five clusters in their experiment with rice genotypes. The distribution pattern of the genotypes indicated that the maximum eight entries were grouped into the cluster II followed by seven in cluster IV, six in cluster V. Among five clusters, cluster I and III contained the lowest (5) number of genotypes

Table 4. Distribution of $\mathbf{3 1}$ aus rice genotypes into five clusters

\begin{tabular}{|c|c|c|c|}
\hline Cluster & $\begin{array}{l}\text { No. of } \\
\text { genotypes }\end{array}$ & $\begin{array}{c}\% \\
\text { Total }\end{array}$ & Name of genotypes \\
\hline I & 05 & 16.13 & Bagunbichi, Aus dhan, V-3, Jaymori, Kalo Aus \\
\hline II & 08 & 25.81 & $\begin{array}{l}\text { Jteric, V-2, V-4, Minikit, Chaina, Saith shail, } \\
\text { H-12, Kadidet }\end{array}$ \\
\hline III & 05 & 16.13 & Hashikalmi, Kalo dhan, Porangi, Kalo hizli, Porangi \\
\hline IV & 07 & 22.58 & $\begin{array}{l}\text { Digha bawalia, Hanuman jata, Sondamoni, Raitul, } \\
\text { Kuchmuch, Puitra aijang, Adub Alli }\end{array}$ \\
\hline $\mathrm{V}$ & 06 & 19.35 & $\begin{array}{c}\text { Boula, Sadey Aus, Mallika, Bar dhan Aus, } \\
\text { Bar dhan Aus, H-171 }\end{array}$ \\
\hline
\end{tabular}

Intra and inter-cluster distance are presented in Table 5. The inter-cluster distances in almost all of the cases was higher than the intra-cluster distance indicating that wider diversity was present among genotypes of distant groups. The germplasm were traditional and they showed high variability between them which was revealed from the results of intra and inter-cluster distance values. Here the highest intra-cluster value was 0.637 and the highest inter-cluster value was 10.168 , which clearly indicated variability's in the germplasm of different clusters. However, lower values in clusters III (0.580) and IV (0.525) was observed due to lower variation in all morpho-agronomic data within these groups. The intra-cluster distances were low for all the six clusters with the range of 0.525 in cluster IV to 0.637 in cluster II which indicated apparently homogeneous nature of the genotypes within the clusters. The results were supported by the findings of Siddique et al. (2010 and 2011) in rice. The intercluster distances ranged from 3.352 to 10.168 and PCoA scores also indicated a high degree of genetic diversity among the genotypes. Regarding inter-cluster distance, cluster II showed the maximum genetic distance (10.168) from cluster V followed by cluster III (9.077) from cluster V, Cluster I (8.495) from cluster $\mathrm{V}$ and so on. Cluster V produced the highest inter-cluster distances $\left(\mathrm{D}^{2}\right.$ values $)$ with all other clusters except IV suggesting wide diversity between the genotypes and the genotypes in these clusters could be used as parents in 
hybridization program for getting transgressive segregants (Saini and Kaiker, 1987). Moderate inter-cluster distance was observed between cluster II and III (6.123), followed by cluster III and IV (4.774), cluster I and IV (4.463). The minimum inter-cluster diversity was observed between cluster I and III (3.352), indicating that the genotypes of these clusters were genetically closed. The results were supported by the findings of Islam et al. (2014) in Sada jira rice germplasm.

Table 5. Intra (bold) and inter-cluster distances $\left(D^{2}\right)$ for 31 Aus rice genotypes

\begin{tabular}{|c|c|c|c|c|c|}
\hline Clusters & $\mathrm{I}$ & II & III & IV & $\mathrm{V}$ \\
\hline I & 0.620 & 7.785 & 3.352 & 4.463 & 8.495 \\
\hline II & & 0.637 & 6.123 & 7.727 & 10.168 \\
\hline III & & & 0.580 & 4.774 & 9.077 \\
\hline IV & & & & 0.525 & 4.979 \\
\hline V & & & & & 0.605 \\
\hline
\end{tabular}

The highest cluster means for yield, effective tiller number and grain length, were obtained from cluster I (Table 6). The highest plant height, flag leaf length, culm length, days to flowering, days to maturity, filled grains per panicle and panicle length were found in cluster V. Moreover, the highest mean values for lengthbreadth ratio and 1000 grain weight were observed in cluster II and III, respectively. None of the 14 characters had the highest mean value under cluster IV. On the other hand, the lowest mean value for yield, culm length, plant height and grain breadth were found in cluster II, cluster III for flag leaf length, flag leaf width, days to flowering, days to maturity, panicle length and filled grains per panicle, cluster IV for grain length and length-breadth ratio. Again, the lowest cluster mean for 1000 grain weight and effective tiller number were observed in cluster I and V, respectively.

Mean performance of different clusters for the characters studied revealed that the maximum good characters were accumulated in cluster I and as a result higher grain yield $(10.17 \mathrm{~g} /$ hill) was obtained in this cluster. Moreover, it was interesting that in most of the cases cluster $\mathrm{V}$ produced the highest inter cluster-value with all other clusters. Therefore, the genotypes of cluster I and $\mathrm{V}$ can be used in hybridization programme to produce higher yielding genotypes. 
Table 6. Cluster means for fourteen characters in Aus rice genotypes

\begin{tabular}{lllll|l|l}
\hline \multicolumn{1}{c}{ Characters } & \multicolumn{1}{c}{ I } & \multicolumn{1}{c}{ II } & \multicolumn{1}{c}{ III } & \multicolumn{1}{c}{ IV } & \multicolumn{1}{c}{ V } \\
\hline Flag Leaf Length (cm) & 47.12 & 43.88 & 40.76 & 48.17 & 53.37 \\
Flag Leaf Width (cm) & 1.25 & 1.15 & 0.96 & 1.15 & 1.19 \\
Days to flowering & 88.80 & 91.62 & 82.40 & 91.43 & 98.17 \\
Days to maturity & 119.6 & 122.12 & 112.6 & 121.71 & 129.50 \\
Culm length(cm) & 101.96 & 68.60 & 90.48 & 107.97 & 110.18 \\
Panicle length (cm) & 24.20 & 24.48 & 22.36 & 24.86 & 27.23 \\
Plant height (cm) & 126.16 & 93.07 & 112.84 & 132.83 & 137.42 \\
Effective tiller (no.) & 10.80 & 9.63 & 10.20 & 9.14 & 8.67 \\
Filled grains per panicle (no.) & 66.40 & 74.25 & 56.32 & 89.29 & 132.33 \\
Grain length (mm) & 9.07 & 8.50 & 8.56 & 8.34 & 8.48 \\
Grain breadth (mm) & 3.17 & 2.72 & 3.03 & 2.82 & 2.83 \\
1000 grain weight (g) & 22.40 & 23.93 & 25.06 & 24.53 & 24.43 \\
Length-breadth ratio & 2.43 & 2.69 & 2.44 & 2.41 & 2.63 \\
Yield/hill (g) & 10.17 & 7.10 & 8.64 & 8.17 & 7.69 \\
\hline
\end{tabular}

Joshi and Dhawan (1966) reported that inclusion of more diverse parents (within a limit) is believed to increase the changes for obtaining stronger heterosis and give broad spectrum of variability in segregating generations. Therefore, more emphasis should be given on cluster I and V for selecting genotypes as parents for crossing with the genotypes of cluster II, which may produce new recombinants with desired traits. While, cluster II had the lowest cluster mean value for culm length, plant height, grain breadth and yield.

Contributions of the characters towards divergence are presented in Table 7. The canonical vector analysis revealed that the both vectors (vector 1 and 2) were not found positive for any of the 14 characters. Negative values for the two vectors for flag leaf length, culm length, panicle length, plant height and filled grains per panicle indicated the least responsibility of both the primary and secondary differentiation. However, positive absolute values of vector 1 and negative values for vector 2 for the traits effective tiller, grain breadth and yield indicated the responsibility of primary differentiation. On the contrary, negative absolute values for vector 1 and positive values for vector 2 for the traits of flag leaf width, days to flowering, days to maturity, grain length, 1000 grain weight and length-breath ratio indicated the responsibility of secondary differentiation. From the above result, it is assumed that Vector 1 obtained from PCA expressed that effective tiller, grain breadth and yield were those characters had some contribution to genetic divergence whereas in Vector 2, flag leaf width, days to flowering, days to maturity, grain length, 1000 grain weight and length-breath ratio played their role in genetic divergence. 
Table 7. Relative contributions of the fourteen characters to the total divergence in Aus rice

\begin{tabular}{c|c|c}
\hline Traits & Vector 1 & Vector 2 \\
\hline Flag Leaf Length $(\mathrm{cm})$ & -0.3302 & -0.2150 \\
Flag Leaf Width $(\mathrm{cm})$ & -0.2078 & 0.0492 \\
Days to flowering & -0.4240 & 0.0794 \\
Days to maturity & -0.4222 & 0.0678 \\
Culm length $(\mathrm{cm})$ & -0.2402 & -0.3695 \\
Panicle length $(\mathrm{cm})$ & -0.3222 & -0.0250 \\
Plant height $(\mathrm{cm})$ & -0.2679 & -0.3560 \\
Effective tiller no. & 0.0768 & -0.0530 \\
Filled grains per panicle (no.) & -0.3696 & -0.1969 \\
Grain length (mm) & -0.1107 & 0.3411 \\
Grain breadth (mm) & 0.2366 & -0.4140 \\
1000 grain weight (g) & -0.0356 & 0.1135 \\
Length-breadth ratio & -0.2004 & 0.5013 \\
Yield/hill $(\mathrm{g})$ & 0.0661 & -0.2883 \\
\hline
\end{tabular}

It is assumed that, the maximum amount of heterosis will be exhibited in cross combinations involving the parents that belong to most divergent clusters. However, for a practical plant breeder, the objective is not only high heterosis but also to achieve high level of yield and reducing the life duration. In the present study the maximum distances existed between cluster II and V. However, considering the cluster means and inter-cluster distances crosses between the genotypes of cluster I and cluster II, cluster I and cluster V would exhibit high heterosis as well as higher level of yield potential. So, based on this result, the genotypes under cluster I, cluster II and cluster V might be selected for future breeding programme.

\section{References}

Ahmed, M. S., K. Akter, M. Khalequzzaman, E. S. M. H. Rashid and M. K. Bashar. 2010. Diversity analysis in Boro rice (Oryza sativa L.) accessions. Bangladesh J. Agril. Res. 35(1): 29-36.

Ahmed, M. S., M. K. Bashar and A. K. M. Shamsuddin. 2016. Study of Qualitative Characters of Balam Rice (Oryza sativa L.) Land Races of Bangladesh. Rice Genomics and Genetics. 7(1): 1-8.

Akter, N., M. Z. Islam, A. Bhuiya, M. A. Siddique and M. Khalequzzaman. 2017. Distinctness of 45 irrigated rice (Oryza sativa L.) landraces of Bangladesh through agro-morphological traits. Eco-friendly Agril. J. 10(07): 100-107. 
Anonymous. 2015. Statistical Yearbook of Bangladesh. Bangladesh Bureau of Statistics. Ministry of Planning, Govt. of Bangladesh. p.49,92.

Belaj, A., Z. Satovic, L. Rallo and I. Trujillo. 2002. Genetic diversity and relationship in olive germplasm collection as determined by RAPD. Theor. Appl. Genet. 105(4): 638-644.

Bisne, R. and A. K. Sarawgi. 2008. Agro-morphological and quality characterization of badshah bhog group from aromatic rice germplasm of Chhattisgarh. Bangladesh J. Agril. Res. 33(3): 479-492.

BRRI (Bangladesh Rice Research Institute). 2015. BRRI Annual Report of 2014-15.

Chauhan, V. S. and B. B. Singh. 1982. Heterosis and genetic variability in relation to genetic divergence in soybean. Indian J. Genet. PI. Breed. 42(2): 324 - 328.

Chakravorty A., P. D. Ghosh and P. K. Sahu. 2013. Multivariate Analysis of Phenotypic Diversity of Landraces of Rice of West Bengal. American J. Exp. Agric. 3(1): 11023.

De, R. N., R. Seetharaman, M. K. Sinha and S. P. Banerjee. 1988. Genetic divergence in rice. Indian J. PI. Breed. Genet. 48(2): 189-194.

Fukai, S. and M. Cooper. 1995. Development of drought resistant cultivars using physiomorphological traits in rice. Field Crops Res. 40: 67-86.

Habib, S. H., M. K. Bashar, M. Khalequzzaman, M. S. Ahmed and E. S. M. H. Rashid. 2005. Genetic Analysis and Morpho-physiological Selection Criteria for Traditional Biroin Bangladesh Rice Germplasms. J. Biol. Sci. 5(3): 315-318.

Hossain, M. 1995. Sustaining food security for fragile environments in Asia: achievements, challenges and implications for rice research. In : fragile lives in fragile ecosystems. Proceedings International Rice Research Conference, 13-17 Feb,1995, Manila. Philippines. International Rice Research Institute. 3-23 p.

Islam, M. Z., M. A. Siddique, E. S. M. H. Rashid, M. S. Ahmed and M. Khalequzzaman. 2014. Genetic Diversity in Sadajira rice (Oryza sativa L.) germplasm. The Agriculturists. 2(1): 26-32.

Islam, M. Z., M. Khalequzzaman, M. K. Bashar, N. A. Ivy, M. M. Haque and M. A. K. Mian. 2016. Variability assessment of aromatic and fine rice germplasm in Bangladesh based on quantitative traits. The Sci. World J.1-14.

Joshi, A. B. and N. L. Dhawan. 1966. Genetic improvement of yield with special reference to self fertilizing crops. Indian J. Genet. PI. Breed. 26(1): 101-113.

Mahalanobis, P. C. 1936. On the generalized distance in Statistics. Proc. Natl. Inst. Sci., India. 2: 49-55.

Mau, Y. S., J. E. R. Markus, S. S. Oematan, A. S. S. Ndiwa, D. D. Handoko, A. Nasution and K. Makbul. 2017. Genetic diversity of red and black upland rice accessions from East Nusa Tenggara, Indonesia as revealed by agro morphological characters. Biodiversitas. 18(1): 197-211.

Moukoumbi, Y. D., M. Sie, R. Vodouhe, B. N. Dri, B. Toulou, S. A. Ogunbayo and A. Ahanchede. 2011. Assessing phenotypic diversity of interspecific rice varieties using agro-morphological characterization. Journal of Plant Breeding and Crop Science. 3(5): 74-86. 
Rao, C. R. 1952. Advanced statistical method in biometries research. John Wiley and Sons. New York. p. 390.

Roy, A. and D. V. S. Panwar. 1993. Genetic divergence in rice. Oryza, 30: 197-201.

Pathan, M. S., E. Haque, N. M. Miah and M. A. A. Miah. 1993. Genetic diversity in rice varieties released and recommended by BRRI. Bangladesh J. Bot. 22(2): 161-166.

Saini, H. C. and U. S. Kaiker. 1987. Genetic diversity in opium poppy. Indian J. Genet. 47(3): 291-296.

Selvakumar, K. S., G. Soundrapandian and A. Amirthadevarathinam. 1989. Genetic divergence for yield and yield components in cold tolerant rice. Madras Agril. J. 76(12): 688-694.

Siddique, M. A., M. Khalequzzaman, M. Z. Islam, M. S. Ahmed and E. S. M. H. Rashid. 2013. Genetic diversity in local Boro rice (Oryza Sativa L.) genotypes of Bangladesh. Bangladesh J. Pl. Breed. Genet. 26(1): 19-24.

Siddique, M. A., M. Z. Islam, M. Khalequzzaman and M.S. Ahmed. 2011. Genetic diversity in rice (Oryza sativa L.) landraces of hilly areas in Bangladesh. Bangladesh J. PI. Breed. Genet. 24 (2): 25-30.

Siddique, M. A., E. S. M. H. Rashid, M. Khalequzzaman, M. Z. Islam, M. S. Ahmed and M. H. K. Baktiar. 2010. Genetic diversity of local rainfed rice (Oryza Sativa L.). Bangladesh J. Pl. Breed. Genet. 23(2): 41-46.

Singh, P. 1983. Studies on genetic variability and diversity of rice. Madras Agric. J. 70(7): 436-440.

Singh, R. K. and B. D. Chaudhury. 1985. Biometrical methods in quantitative genetic analysis. Kalayoni publishers. New Delhi. p. 318.

Sohrabi, M., M. Y. Rafii, M. M. Hanafi, A. S. N. Akmar and M. A. Latif. 2012. Genetic diversity of upland rice germplasm in Malaysia based on quantitative traits. The Scientific World Journal, 416291: 1-9.

Talukder, M. M. H. 2011. Governance crisis in production and distribution of hybrid seeds and its impact on market behavior and trust deficit among farmers of Bangladesh. Proceedings of the SAARC Seed Congress \& Fair, Dhaka, Bangladesh. pp: 48-57. 